Article

\title{
Darkness on Screen: Subjectivity-Inducing Mechanisms in Contemporary Estonian Art Film
}

\section{DE DE GRUYTER}

OPEN 


\section{ABSTRACT}

The main purpose of the article is to bring more clarity to the concept of art film, shedding light on the mechanisms of subjective reception and evaluating the presence of subjectivity-inducing segments as the grounds for defining art film. The second aim is to take a fresh look at the littlediscussed Estonian art cinema, drawing on a framework of cognitive film studies in order to analyse its borders and characteristics. I will evaluate the use of darkness as a device for creating meaning, both independently of and combined with other visual or auditory devices. The dark screen, although not always a major factor in the creation of subjectivity, accompanies the core problem both directly and metaphorically: what happens to the viewer when external information is absent? I will look at the subjectivity-inducing devices in the films of two Estonian directors, Sulev Keedus and Veiko Ounpuu. For the theoretical background, I rely mostly on Torben Grodal's idea about the subjective mode as a main characteristic of art film, and the disruption of character simulation as the basis for the film viewer's subjectivity.

\section{INTRODUCTION}

For Estonian cinema, the last two decades has been a time of seeking its identity and continuously recreating its language, which has been characterised by a renewal of its positions both in technical and stylistic terms. The early 1990s brought a change of paradigm - the Soviet modes of production were disrupted and new types of practices and organisations (e.g., private film companies instead of state-governed production units) had to emerge. Now a model of European-style state co-financing through the Estonian Film Institute and Culture Endowment of Estonia is quite well established.

The post-Soviet feature films have mostly been story-driven for the same reasons as elsewhere - financing feature films is at least partially a business undertaking involving risks and calculations, requiring rather conservative, tried and tested solu- tions and projects in order to gain support. Additionally, considering the context of specific film types, we can observe the strong international position of independent Estonian animation. We can speculate that animation has been attracting a significant part of the experimental energy, mainly leaving feature films with the task of finding a balance between the popular and the peculiar.

The style of a limited number of Estonian filmmakers can be described as having art cinema properties according to the seminal work by David Bordwell, "The Art Cinema as a Mode of Film Practice" ([1979] 1999), Narration in Fiction Film (1986) and his later works on continuity editing, e.g. Intensified Continuity: Visual Style in Contemporary American Film (2002), as well as characteristics more recently defined by Annette Kuhn and Guy Westwell (2012). I will focus on the films by Sulev Keedus - 
Georgica (Estonia, 1998) and Letters to Angel (Kirjad Inglile, Estonia, 2011), and Veiko Õunpuu - Autumn Ball (Sügisball, Estonia, 2007) and The Temptations of St. Tony (Püha Tõnu kiusamine, Estonia, 2009). Works by other directors, such as Marko Raat, Rainer Sarnet, and Kadri Kõusaar, also contain elements relevant to art film, but these seem to be less prominent in creating subjectivity. These works, as well as the subjectivity in Soviet Estonian cinema, would no doubt provide an interesting field of study for the future.

The concept of art film seems unavoidable in film studies, since it also functions as a labelling tool in various institutions of cinema. The Oxford Dictionary of Film Studies defines art cinema as film practices having certain aesthetic properties, most importantly loose, episodic, or elliptical narration, as well as image and sound that take precedence over plot. These properties are usually attributed to the artistic vision of the director as the auteur. The boundary between art cinema and avant-garde film has seemed fuzzy, especially given their shared roots in modernism (Kuhn, Westwell 2012: 18), but it has also been observed that art film is "neither mainstream nor avant-garde" (Galt, Schoonover 2010: 5). This allows us to posit art film somewhere between mainstream and avant-garde.

Rosalind Galt and Karl Schoonover draw attention to the problems of definition that art film poses for film scholarship: "Is art cinema a genre, in the way that mainstream criticism often uses the term? A mode of film practice, as David Bordwell claims? An institution, as for Steve Neale? A historically unprecedented mode of exhibiting films, in Barbara Wilinsky's terms? Is it ... a language able to disarticulate excess, style and politics from taste and to map the promiscuous hybridity of cinematic forms?" (Galt, Schoonover 2010: 6) Galt and Schoonover see this plurality not just as an ambiguity of art film as a critical term, but as a central part of its specificity, a positive way of delineating its discursive space (ibid.). Transcending categories seems to be in the nature of art film.
Recent years have seen a blurring of the formal conventions between mainstream and art cinemas, though many of the institutional differences (in modes of production, distribution and exhibition) remain in place. With today's globalisation, art cinema has become a transnational phenomenon as the international cultural film plays to a niche market, with the director regarded as a brand (Kuhn, Westwell 2012: 19). The relative vagueness of definition and blurring of borders mentioned above calls for a new, more technical understanding of art film.

First, I see some problems emerging from the convergence of art film and auteur cinema. Leaving aside the postmodern attempts to fend off the Author in favour of the Text, and various approaches emphasising collective authorship (e.g., Sellors 2007), even if we do not necessarily try to locate the meaning of film at the point of reception, several contradictions can be pointed out. A director, or even a producer, of a blockbuster can be treated as a brand (thus having significant authorial connotations) by a marketing system, as well as by the viewer/consumer. Probably one of the freshest and most provocative point made by François Truffaut and other French film critics involved in the periodical Cahiers du cinéma in the middle of 1950s was recognising certain Hollywood directors as auteurs. The films of the arguably the most vivid example of auteurship, Alfred Hitchcock, were popular studio productions and cannot be considered to be representations of art film per se. The existentialist adjectives of freedom or authenticity assigned to the works of auteurs (e.g., Stam 2000: 83) could easily characterise art films as well, but I propose that this link will cause, at least in the context of this article, some confusion and blurriness. As Graham Petrie has provocatively observed, "the auteur theory was essentially an attempt to by-pass the issue of who, ultimately, has control over a film. [---] By distilling something called "personal vision" from a film, and marketing this as the "essence" of its success, it 
was hoped to evade all the sordid and tedious details of power conflicts and financial interests that are an integral part of any major movie project." (Petrie [1973] 2008: 110) An even more relevant reason to leave auteur cinema aside and focus on the art film would be that the latter is more attributable to film text and the mode of its reception, allowing us to be more technical. Thus I suggest that a more explicit distinction between auteur cinema and art cinema should be made, seeking presumable ways for defining art film by the means of disembodiedness (Grodal 2009: 208), and via the latter, by viewer's subjectivity.

It is significant that while David Bordwell's benchmark works "The Art Cinema as a Mode of Film Practice" and Narration in Fiction Film still touch upon authorship, they do so rather casually, having their emphasis on textual aspects. At the centre of Bordwell's approach is the view of art cinema as a specific mode of narration, in which syuzhet (cюжem, plot) is less redundant than in classical film (Bordwell 1986: 205), causality is tampered with or represented far less explicitly (ibid.: 210), and the film suggests, with its gaps and ellipses, ambiguity and connotative reading (ibid.: 212). A crucial point where all these characteristics converge is the intensified activity of the viewer. In order to have a better understanding of the mechanisms behind that activation I will draw, in particular, on recent cognitive film theory. I suggest that Torben Grodal's (2009) idea about character simulation as the default mode of viewing, as well as the disruption of that simulation as the basis for emerging subjectivity in the viewer, can be claimed as the crucial component or even the main device of art film. The applicability of simulation/subjectivity opposition will be tested on the aforementioned small body of Estonian film.

The question of confluence between visual and auditory information will be touched upon briefly. In order to narrow down the topic I will concentrate on the visual rather than the auditory, although never denying the crucial role of sound in the construction of meaning or the simulation of an environment, or creating the viewer's subjectivity in art film mode.

Keedus, and especially Õunpuu, have repeatedly been called art-house directors by the media and film criticism, but without much deeper analysis of the relevant details in their style. Peeter Torop is one of the few to describe how Keedus's poetics gains its idiosyncrasy and universality at the same time. Using the sensitive confluence of visual and auditory information, the author consciously sets his text into an intertextual relationship with Tarkovsky's Stalker (Сталкер, Russia, 1979), among others (Torop 1999). On the one hand, it proves that many specific elements in film work rather unambiguously without further explanation, powered by the shared cultural time-space and psychological properties of the audience, carrying the connotation of "art", "art house", "independent", "subjective", or sometimes just "weird". On the other hand, as I aim to suggest with my article, this cultural/psychological explanation fares even better in the framework of Grodal's theory. Being conscious of the problems that may arise while defining art film, it is clear that, in the scholarly context, a "gut feeling" is not enough. Thus I also hope to contribute to the better understanding and definition of art film, altogether.

Last but not least, when the 100th anniversary of Estonian film was celebrated in 2012, The Film Motif of the Century was chosen by a poll. Although not winning, "darkness" was included in the set of a few nominated motifs with "ambiguous eyes" and "a bare tree". Though "ambiguous eyes" won, darkness definitely has at least the same symbolic, or even literal, power for inducing subjective meanings in viewer. The more general aim of my article rises out of this. I will attempt to delineate what type of subjectivity Estonian art film prefers and what position the use of the darkness sequences occupies therein.

\section{DAVID BORDWELL ON ART FILM}

Marking off a segment on the map of a theoretical territory is a task that has, in a 
broader sense, quite similar starting points for different fields of study. For instance, the changes in culture during the decades around the turn of the twentieth century produced similar challenges both for literary theory and art theory. We can retrospectively claim that one of the main tasks of these scholarly undertakings was describing the defining factors of "popular" and "elitist" art, taking a closer look at the differences between the functioning of popular and modern literature, or drawing borders between "art for mass consumption" and "art for art's own sake". This significant distinction can be approached from the perspective of the production and reception of text. In reception studies, the play between denying and fulfilling the audience's expectations is elegantly touched upon in the concept of the "horizon of expectations" (Erwartungshorizont) by Hans-Robert Jauss (Jauss, Benzinger 1970:12-14). The fulfilment, clearly, correlates with popular text, while surprise or ambiguity correlates with the "art mode". The dynamic nature of Jauss's concept lets the reference point float depending on the specific reader or spectator. Considering the construction of text, alongside other disciplines, semiotics of culture (especially of the Tartu-Moscow school) has helped us see the position of a certain text in its contextual environment, assessing its connections with other texts, as well as evaluating the flow of information on the scale of known/unknown or old/ new. The sufficient amount of novel information correlates with more exclusive, artoriented texts. Roman Jakobson's six functions of language (e.g., Waugh 1980) can be seen as a solid basis for a textual theory that considers both sides - the production and reception. Jakobson's phatic function is more important in popular texts, metalingual and poetic function in art-oriented production.

The American film theorist and historian David Bordwell sees art film as a distinctive practice in the realm of filmmaking. In his words, art film possesses a definite historical existence, a set of formal conventions, and implicit viewing procedures.
Art film, in the long run, gains most of its historical and cultural legacy from literary modernism; in the realm of cinema, its roots are grounded in early film d'art, German Expressionism, French Impressionism and post-war Neorealism (Bordwell [1979] 1999: 716).

Defining art film, the early Bordwell, probably not reflecting explicitly on his path, grabs for the tools of semiotics, not unlike the ones of the Tartu-Moscow school. He sets up a distinction between classical cinema and art cinema, together constituting a binary opposition. Art cinema, Bordwell says, defines itself against the classical narrative mode, and especially against the cause-effect linkage of events. These linkages become looser and more tenuous in art film. The classical mode, prevailing and widespread, and unmarked in Yuri Lotman's sense (2004: 53), rests upon particular assumptions about narrative structure, cinematic style and spectatorial activity. Narrative time and space are constructed to represent the cause-effect chain, narrative itself projecting its action through the goal-oriented characters. The viewer makes sense of the classical film through the criteria of verisimilitude (is $x$ plausible?), of generic appropriateness (is $x$ characteristic of this sort of film), and of compositional unity (does $x$ advance the story?) (Bordwell [1979] 1999: 717). To achieve its ends, classical cinematic representation has established an idiosyncratic "language" or system of meaning, which, on the one hand depends on cultural conventions and continuously building on its history, and on the other hand, as we will see later, depends heavily on psychological properties, the functioning of the brain, and perception system of the human species. The art cinema mode, to a great extent, behaves similarly to fine arts and experimental literature, trying to deconstruct the signifying practices of the classical mode, breaking down its conventions, denouncing it, and depending on it at the same time.

Bordwell claims that art cinema motivates its narratives based on two principles: realism and authorial expressivity. Art 
cinema, defining itself as a realistic cinema, shows us real locations and real problems (alienation, lack of communication, etc). Even more important, art cinema uses "realistic" - that is, psychologically complex - characters. Art cinema is classical in its reliance on psychological causation, whereas the characters of classical narrative have clear-cut traits and objectives, the characters of art cinema lack defined desires and goals. As the Hollywood protagonist speeds directly towards the target, the art-film character slides passively from one situation to another. However, his or her itinerary is not completely random. According to Bordwell, the progression of narrative can take the form of a trip or a search, among others. Art cinema allows the characters to express their psychological states; they often tell one another autobiographical events, fantasies, and dreams (Bordwell [1979] 1999: 718).

Bordwell touches upon subjectivity while discussing the problems of realism. He says that art cinema's "realism" encompasses a spectrum of possibilities. The options range from a documentary factuality to intense psychological subjectivity (Alain Resnais's Hiroshima, mon amour, France/Japan, 1959). The "illusion/reality" dichotomy of art film results when two impulses meet in the same film. Thus, art cinema leaves room for two reading strategies: violations of classical conceptions of time and space are justified as the subjective reality of complex characters; manipulations of duration are justified realistically or psychologically. Bordwell concludes that a commitment to both objective and subjective verisimilitude distinguishes art cinema from the classical narrative mode ([1979] 1999: 719).

The subjectivity of a film character is accompanied by a set of problems, as the depiction of the character's (unnatural) experience has always coincided with passages that are intentionally estranging for the viewer. We can notice the "embedded" subjective sequences in mainstream films throughout the history of cinema from Griffith to the contemporary subgenre of drug films (The Acid House, United Kingdom, 1998, Paul McGuigan; Spun, USA, 2002, Jonas Akerlund; The Beach, USA/United Kingdom, 2000, Danny Boyle), which employ time manipulation and various audiovisual effects in order to convey the character's subjective experience under the influence of drugs. Here we cannot claim with any certainty that these means of expression are loans from the art film mode. In film history, various devices for conveying the subjective feelings of a character have been continuously sought for and developed. This demonstrates, firstly, a wide potential of flexibility between the art and classical modes, and furthermore, that the subjectivity of a film character is a special case that must be treated with caution. For that reason, while I believe subjectivity is still one of the most important keys to understanding art film, a character's subjectivity as a determinate factor must be left aside, at least initially.

The subjectivity and essence of "art film" can also be approached by considering the film style, or the construction mode of a text, or more precisely, the editing as one of the defining constructional activities in the film medium. In his later works, Bordwell frequently touches on continuity editing, as well as other codes familiar to the viewer. Continuity editing, developed and crystallised in classical Hollywood cinema, mostly from the 1910s through the 1930s, has been a dominant style for a long time. The aim of continuity editing is to create smooth transitions of time and space, employing such devices as the establishing shot, 180degree rule, eyeline match, diegetic sound, etc. According to Bordwell's analysis of the visual style of contemporary American film, even the changes in mainstream cinema do not justify the inception of a new paradigm or "post-classical period", because nearly all the scenes in contemporary massmarketed movies are staged, shot and cut according to a selection and elaboration of options already available on the classical filmmaking menu. Bordwell sees more rapid editing, bipolar extremes of lens lengths, closer framings in dialogues, and a free-ranging camera as the markers of 
intensified continuity, which is just the intensification of already established techniques (Bordwell 2002: 20). If we scrutinise the position of art film in relation to the aforementioned stylistic canons, the possibility of describing art film as a deliberate deviation from continuity editing must be taken with a grain of salt. As Bordwell states, even the films outside the mainstream do not necessarily reject (intensified) continuity (ibid.: 21).

The semiotic approach, on the other hand, emphasises the role of codes, which the viewer must understand in order to grasp the meaning of a film. In his essay "The Viewer's Share: Models of Mind in Explaining Film", Bordwell alludes to the view that continuity editing could be understood as one of the codes that makes a film comprehensible for the viewer (Bordwell 2012). But instantly, a shadow would be cast by one of the most fundamental debates in contemporary film theory, namely between the code-centred, representation-oriented view and the more realist, cognitivist-based approach. As a cognitivist, Bordwell mostly agrees with Noël Carroll ([1985] 1996), Joseph Anderson (1996) and other cognitivists, that filmic perception demands minimal specialised code-reading, depending largely on the automatic skills of ordinary perception, which have filtered through millennia of evolution (Bordwell 2012). In Poetics of Cinema, he attempts to provide a model for the spectators' response to narrative film, arguing that the spectator draws on real-world knowledge and awareness of narrative conventions, going beyond the information directly provided in the film (Bordwell 2008: 11-133). We can conclude that the seemingly code-independent response is more relevant in mainstream films; in art films the importance of culturally learned schemata or knowledge about the idiosyncrasies of the filmmaker gives us some crucial clues for understanding them.

\section{COGNITIVE FILM STUDIES:} SPECTATOR'S SUBJECTIVITY

Cognitivists are most interested in the spectator level. Bordwell, being one of the pioneering cognitive film theorists, provides a concise description of how an art film's authorial intentions are understood by the spectator. A competent viewer, while watching a film, expects less order in the narrative and more coherent stylistic signatures in the narration. The deviations from the classical canon - an unusual angle, a stressed bit of cutting, a prohibited camera movement, an unrealistic shift in lighting or setting - in short, any breakdown of the motivation of cinematic space and time by cause-effect logic - can be read as "authorial commentary" (Bordwell [1979] 1999: 720), or understood as a device of ambiguity. Having certain gaps and problems, art film demands a particular reading procedure (ibid.: 721). As a cognitivist who has an understanding of the evolutionary biology influencing every facet of our film perception, Bordwell claims that whenever we are confronted with a problem in causation, temporality, or spatiality, we first seek a realistic motivation (e.g. "Is the character's mental state causing the uncertainty?"). If that cannot be found, we then seek authorial motivation ("What is being "said" here?"). Quite often, as Bordwell also claims, uncertainties are left to be ambiguous, being understood as such, as obvious uncertainties (ibid.).

We could be fully satisfied with Bordwell's view of the spectator's approach to ambiguities only if we ignore the human species' constant urge for creating meaning in anything it encounters in its environment. As another cognitivist, Joseph Anderson claims, the perceptual system cannot tolerate ambiguity; it must obtain information it can act upon; indecision is potentially fatal (1996: 45). Though we can differentiate between the perceptual system and the meaning-making system, we have to conclude that what is intrinsic to the former is also inherent to the latter. The mind is pragmatic in its own way, attempting to construct a coherent world out of external stimuli. Doing that, we may have different mental models for understanding different types of films or different sections of the same film. 
In the viewing process we can encounter several cues, which let us, exactly as Bordwell stated, decide that the segment we see is meant to be ambiguous from the start, as in the case of the aforementioned drug films that convey the character's subjective state. But at other times, the art film mode sets the viewer into a specific state where this abstract ambiguity-evaluation cannot emerge. Instead, the viewer's personal meanings and interpretations quickly start to develop. Although the level of that personalness is under question, because "personal" interpretations could be intentionally cued by the filmmaker's skilful manipulation of connotative signs, I see a text with larger or smaller gaps within the signifying structure of film. Filling these gaps requires more active viewers; and what's more, also develops them. Here we can speak chiefly of subjectivity that emerges in specific film segments and is induced by these gaps. It works on the level of a spectator, who, enjoying or suffering a temporary break from narrative, embarks on his/her own train of thoughts. I would claim (partly influenced by Grodal's work) that this kind of subjectivity is most relevant to the art film mode.

In order to increase the contextuality of the description of that subjectivity, we should consider at least one other cognitivist-related explanation. The semio-pragmatics of film deal with the production and transfer of meaning in the context of communication models in which a distinction can be made between the levels of sender and receiver. The dynamics of meaning are heavily dependent on the competence, knowledge base, and psychic disposition of the person viewing the film. Warren Buckland, extrapolating from Dan Sperber and Diane Wilson's theory of relevance in communication (1986) and the semio-pragmatic work of Roger Odin (1995), sums up the most fundamental ideas (Buckland 2000: 78-89). He emphasises that the ontology of a film is not automatically fixed in advance, but is determined through the process of watching (or interpreting) a film. No film can be determined to be inherently fic- tional, documentary, or avant-garde. The same goes for art film: one must be careful not to make absolute claims about it. The other important point concerns film modes (Odin's film semiotics uses a classification of film types, which depend on the cognitive competence of the film's viewer/reader. For example, among eight basic modes Odin distinguishes between spectacle, fictional, artistic, and home movie modes (Buckland 2000: 88-89)). The most important point is that these modes are not mutually exclusive, nor can we overlook the fact that a specific mode is only determined through the process of reading (ibid.). Transferring these ideas to the issue of "art film narration versus classical narration", we can visualise both "modes" existing together within the same film. Consequently, it would be more precise to make a distinction at the level of film segments, not the complete film texts. Thus, we see a film repeatedly entering and exiting the stage of subjectivity.

Buckland also stresses the principle of relevance. A message can be defined as relevant when the receiver in a communication chain exerts an optimal amount of processing effort (in order to decode the message), and the acquired information is new, while relating, at the same time, to the information already acquired by the addressee (Buckland 2000: 84-85). The optimal proportion of new and old information is the premise for processing the information with the least effort and, optionally, the most enjoyment. Based thereon, we can visualise two models. According to the first, in an art film, or more precisely, in a subjective segment thereof, the relevance of communication drops significantly and the message is "understood" differently by the sender and the receiver, or is not understood at all. According to the second model (a more Odinesque one), the classification of art film and classical mode is entirely up to the spectators, who are possibly able read a classical film in the art film mode for personal reasons (for example, having entirely different cultural backgrounds). The position I would like to take still strongly 
acknowledges the evolutional factors in film perception, a certain measure of common practices in viewers (which is finely explicated in Grodal's understanding of mainstream film as simulation), and is consequently closer to the former model, without denying the adjustments and remarks of the latter.

Before turning greater attention to Grodal, here are a couple of observations about the role of sound. As Thomas Elsaesser and Malte Hagener (2010) state, the role of different perceptual channels especially the way they relate to each other in filmic experience - is still under dispute. Elsaesser emphasises the role of sound in film history, claiming that film was never a mute medium. He shows how sound, being three-dimensional, helps to create space around the two-dimensional visual plane. Elsaesser believes that the main function of sound is anchoring and stabilising the viewer's body in space (Elsaesser, Hagener 2010: 131), allowing the situation where a "bodily being is enmeshed acoustically, spatially and affectively in the filmic texture" (ibid.: 132). Since we can hear in complete darkness, sound can provide us with clues about our environment, and vice versa: altering sound from "normal" to ambiguous, the filmmaker can initiate a subjective segment without "alienation" in the visual channel, casting the viewer into a state that can be metaphorically called auditory darkness.

\section{TORBEN GRODAL: EMBODIED VERSUS DISEMBODIED REPRESENTATION}

Grodal's cognitive film theory must be approached in a framework that emerged through the paradigmatic shift in humanities, namely the cognitive turn toward evolutionary bioculturalism. As David and Christine Andrews point out, film studies have largely avoided the biocultural turn that has swept the other humanities fields. This resistance may be rooted in the field's recent distaste for grand theories and in the loose social-constructionist thinking that is a residue of that distaste. On the other hand, a biocultural approach to cinema can offer film studies the necessary and academically defensible assumptions, interpretive tools, and potential ways of conceptualising perennial concerns like authorship and genre (Andrews, Andrews 2012: 58). Ryan Pierson, reviewing Grodal's Embodied Visions, sees the humanities' mistrust of science as, at least, a part of the problem (Pierson 2010: 93). Grodal, at a moment of promise and uncertainty, when film and media scholars want to bring the body into their analyses but are not quite sure how to talk about it, explains several key matters in film aesthetics through the processes and architecture of the always-embodied brain, with a dense bibliography of theoretical and experimental research behind it (ibid.). Pierson finds that Grodal's application of evolutionary psychology as an analytical tool makes him unique. Rather than finding ways to bracket off cultural variations from basic cognition, he looks for a cognitivist explanation of culture itself (ibid.: 94). The chief target of Grodal's polemic is cultural determinism that denies biological factors in the understanding of cultural products, or an unwillingness to acknowledge that we are products of evolution. Grodal is making the case that cultural/historical explanations should fit into a larger, biologically informed framework (ibid.). Pierson sees the possible difficulties in treating short-term changes in culture, as well as privileging the individual psychological factors over social ones in the hierarchy of causation (ibid.: 97-98), as a problem that Grodal's approach may encounter. In a more distinctively opposing camp, Grodal's ambitious approach may cause rather vigorous, but emotion-driven and oversimplifying outbursts. According to Robert Sinnenbrink, Grodal assumes that culture reflects biological foundations, much like "vulgar" Marxists assumed that it reflected the "economic base" (Sinnenbrink 2012: 198). It is obvious that both extremes miss part of the picture - the duality of socio-cultural and biological factors must be accepted and scrutinised in their mutual dynamics. In my opinion, the appearance of cognitive 
approaches, such as Grodal's, should be seen as characteristic of a period when the paradigm is starting to change. In order to introduce the new, the old is inevitably left aside, and after a while, a new balance is established in the system.

As George Lakoff and Mark Johnson have pointed out, when we realise that the mind is inherently embodied, the central parts of Western philosophy (and other practices of thinking that are directly influenced by the idea about the dualism of mind and body) are proven to be wrong. As reason is always embodied, the body has a great influence on any type of mental activity. One of the most significant mechanisms that connect the body to culture is metaphor, and any metaphor, at its deeper level, can be seen as stemming from the imagery of the body or its close environment (Lakoff, Johnson: 1999). Applied to film theory, embodiedness means primarily that film perception is shaped and restricted by our physical properties, our evolutionary history, our habits and goals as organisms functioning in our environment. These goals are tied to affordances, a term coined by psychologist James J. Gibson. Gibson defined as "all action possibilities" latent in our surroundings. The affordances of the environment are what are being offered to the animal, what the environment provides or furnishes, either for good or for ill (Gibson 1986: 127). Basically, all properties of objects that allow an individual to act on these objects (from picking up something off the ground to starting and driving a car) can be considered to be affordances. The term is widely used in cognitive psychology, environmental psychology, industrial design, and probably with most benefit, in the fields that need to model or simulate human conduct, i.e., artificial intelligence, human-computer interaction, and game design.

Grodal's (and most other cognitivists') fundamental claim is that film viewing is based on our standard experience of the world. This is backed up by the evolutionary argument, stating that the need for survival has shaped our perception system to take any stimulation seriously, i.e. first to believe what we see or hear, and give the quickest reaction at least of our "fast thinking" system (Kahneman 2011). Affordances in an artificial environment - one can include film into this category - require similar reactions from us. In that way, affordances are the building blocks of simulation. According to Grodal, the viewer will use all the available information in order to decide on his/ her focus of concern. In general, this focus of concern corresponds to what is popularly called character identification, or more scholarly, agency simulation (I will hereafter use "simulation"). Our capability of watching films is linked to our ability to model and simulate ourselves as seen from the outside (Grodal 2009: 193).

Grodal argues that prototypical art films combine stylistic innovation with a claim to higher meaning (Grodal 2009: 208). Nevertheless, he quickly gives shape to this abstract formulation by observing the correspondence between "higher meaning" and disembodiedness, in contrast to mainstream film, which is based on embodied interaction with an online reality (ibid.). Central to Grodal's theory is the concept of PECMA (perception, emotion, cognition, and motor action) flow. PECMA flow theory describes how film experience relies on a processing flow that follows the brain's general architecture, namely a flow from perception (ear and eye), via visual and acoustic brain structures, association areas, and frontal brain structures to action (motor action) (ibid.: 146). According to Grodal, embodied narratives are based on a full PECMA flow in which perceptions and emotions result in actions (ibid.: 210). The reason why moviegoers do not stand up or start acting while viewing the film is a selfevident and self-inflicted illusion about the duality of mind and body, which lets us be "body snatchers" - a simile from a famous horror movie used by Grodal - by letting our feelings power some of the characters we are watching. "In the cinema," Grodal continues, "our minds give up control of our own bodies, which are quietly placed in seats in dark rooms, and what enter the eyes are emotionally charged audiovisual data of 
relevance for the bodies and minds of characters." (ibid.: 193) Disembodied narratives, by contrast, block the PECMA flow to some degree; here the emotions are channelled into saturated webs of association, and the film narrative as a rule takes place in an inner, subjective world (ibid.: 210).

Disembodied representations may also arise when there is a disruption of "dominant experiences" or affordance-like cues for the character's action (for example, the character's memories or hallucinations are presented to the viewer), or the action perspectives are bleached out, as occurs, for instance, with temps mort - the time when nothing happens in a film. Such experiences are felt to be more permanent than the emotions cued by the ever-changing online narrative; and this sense of permanence is central to the experience of higher meaning (Grodal 2009: 211). In Grodal's description, this "higher meaning" finds close correspondence with "disembodiedness", "disruption of simulation", and "subjective meaning" emerging in the viewer. On the other side are "embodiedness" and "simulation mode", respectively. Seeing the clear and substantive line between these two groups of descriptive terms, I propose, based on the cognitivist goal of grounding our basic-level descriptions on brain processes, an attempt to reduce these two opposing possibilities to an opposition of the simulation and non-simulation mode is at least technically justified in the context of this article. Let us consider these to be the ideal extremes: in actual viewing, the experience related to these modes is always mixed to some measure. While watching classical narrative films (or more precisely, film segments), the simulation mode is prevalent, and while watching art films, the non-simulation mode, or disruption of simulation, gives rise to subjective meanings.

\section{GRODAL ON SUBJECTIVITY}

According to Grodal, the subjective tone will prevail if there are no protagonists in the film, or the characters'/viewers' tendency to act is blocked or impeded. This subjective toning is more connected to intuitive feel- ings and may, at the same time, make the film feel less real (Grodal 2009: 229). Our sense of objectivity or subjectivity depends more on the issue of control than anything that is evaluated on the scale of reality. The experiences allowing us little scope for action (e.g., a lack of affordances in our environment) are simultaneously labelled less real in our minds and more subjective. Thus a subjective feeling corresponds to a situation where the environment does not fully support the action. Action may be blocked because of insufficient visual information. For example, scenes that take place in foggy weather can often be described as subjective. In evolutionary terms, the feelings of subjectivity probably represent warning signals: one must be careful when acting on such little information (ibid.: 230231). Perhaps the most celebrated examples of art film subjectivity come from long takes (such as those in films by Andrei Tarkovsky, Béla Tarr, and others). If a sequence persists beyond the brief time required for the viewer to make all the propositions cued by the images, the mind will shift into subjective mode. Our first procedure in watching a film is to deal with it as a stream of information that cues the construction of objective spaces and processes. If we fail to find anything that can focus our attention, we will shift into an unfocused default mode (ibid.: 233). As we have solved all the imminent "problems" on the screen, our mind switches to a less conscious and more associative mode. Different subjectivityinducing modes have one thing in common: our action-based relationship with the environment is blocked or disturbed.

Grodal, sketching out a typology of the causes of subjectivity in film, distinguishes six main factors: 1) subjectivity by default, stemming from sequences in which there are few or no actions; 2) a represented space that impedes perceptual access;

3) deviant or distorted enactional or perceptual access to a represented space; 4) actions and processes that deviate in certain ways from normal objective actions and processes; 5) situations with a problematic reality status that block interaction; 6) devi- 
ant emotional phenomena and reactions (Grodal 2009: 236). According to this system, darkness falls under the second and third category, distracting the perceptual access to fictional space.

Evidently, the induction of subjectivity is not exclusively dependant on visual information. A filmmaker can trigger the spectator's feeling of subjectivity with the soundtrack, as sound helps to "place" the viewer into the film's time-space. Thus the omission of diegetic sound can suppress the viewer's simulation-like activity in favour of a disembodied experience. Consequently, in order to better understand the mechanisms beyond the spectator's subjectivity, the dynamics of visual and auditory cues must be examined together.

Before moving on to the film analysis, we need to revisit a simple problem that has already been briefly touched on before. Namely, what is the functional difference between darkness in art film and darkness in classical narrative film? Could both be considered the basis for subjectivity? If we take the opposition "simulation/ non-simulation" as a criterion, we can, with some reservations, speak about motivated and unmotivated darkness. Action-motivated darkness functions as an additional component to simulation, not necessarily hindering it, but impeding the simulation marginally. It transforms the added portion of subjectivity into a catalyst of narrative as in horror films (darkness stressing the component of the looming unknown), or in romance sequences (darkness cutting away other affordances and leaving only those relevant to intimacy). The other type of darkness is much less connected to actions and could be defined as unmotivated. This is the one we are interested in.

\section{SUBTLE SIGNS OF SUBJECTIVITY: MORE THAN DARKNESS IN KEEDUS}

In the following sections I will discuss several segments of Keedus's and Õunpuu's films in the context of subjectivity. Darkness can be used on screen as an instrument for impeding the spectator's view, in some con- texts this turns out to be characteristic of art film. Subsequently I will shortly discuss what conditions need to be met in order to claim that a specific darkness segment is appropriate to art film. Then I will analyse the darkness segments of the aforementioned directors, with the intent of applying the previously described cognitive framework to their films, which are labelled arthouse a priori, but not given enough attention in relation to the criteria of such categorisation. My intention is to describe how the disruption of simulation works in the films of these directors, and how significant the view impediment is in their poetics. The following question should also be posed: Are there any devices that work in a similar manner that can functionally replace darkness or view impediment? As the previous semiotic problem belongs to the paradigmatic axis, we should also look at the syntagmatic level and ask about the immediate context of the darkness segments, because the meaning of one element in a sign system always acquires its meaning in confluence with adjacent elements and receiving the impact of the whole structure.

Keedus, both a documentary and feature film maker, is one of the Europe's most personal, serious-minded, and meticulous directors. The multiple layers of his work are revealed to viewers who are able to read them, namely viewers who have knowledge of history, as well as an understanding of symbols, world culture, and human psychology.

Two characters are at the centre of Georgica, his second feature film. The time of the film is not specified but hinted at: it takes place in the 1950s, during the Soviet occupation when Estonian coastline was a closely guarded and restricted border zone. A boy (Mait Merekülski) who has lost his ability to speak is sent to a strange island for the summer, to live with an old man who works as the island guard. The guard, called Jakub (Evald Aavik), keeps bees and performs tasks ordered by invisible powers. For example, at night when bombers target the military artillery range on the island, Jakub has to observe the range with bin- 
oculars and take notes about where the bombs hit. In addition, as a former missionary to the Wakamba people in Kenya, Africa, he is translating Virgil's Georgics (Georgica, 29 BC) into Swahili. The idea of farming, containing hope and commitment, is set against an era that is seemingly post-apocalyptic, looming with dangers and restrictions. The metaphorical meaning is even more significant: there is a need to heal the boy and make him speak again.

I will briefly look at two darkness scenes, both of which are compounds of sub-sequences occurring several times during the film. The first set of darkness shots depicts night bombings, of which the first is simply menacing, but the final one fatal to Jakub. The second set represents the boy's recurring memories and is presented in several parts. In the other shots, darkness does not play any significant role; the overwhelming tonality of the film (shot by the cinematographer Rein Kotov) is golden, soft, and mellow, like light at the "magic hour" of the day.

In the night-bombing sequences, darkness does not disrupt the simulation, but partially hinders it. Only the reflections of the explosions are seen, the sounds of blasts and aircraft engines are heard; but no planes or direct flashes are seen because of the darkness and the choice of camera angle. These shots still provide affordances and, consequently, keep the action going. Darkness can only modify the simulation, slowing it down and partially distancing characters from the reality of the storyworld; thus the loss of the horse and Jakub can be experienced from an emotional distance. The darkness is never impenetrable, rather it functions as background for the action. I suggest that even if the reader/viewer of the film is moving along the border between simulation and subjectivity, the darkness, in this case, only enhances the subjective reading in a limited sense.

The second set of darkness episodes comes from the boy's memory, and is one of the key sequences depicting the origin of the boy's trauma. There is no distinct border between the psychoanalytical dream material and "real memory"; at the first reading of the film, the choice of the dream-like vision may probably prevail, but typically of Keedus's poetics, we seldom encounter anything supernatural (except, in Georgica, the scene with dead seamen on board an abandoned ship; a brief scene framed by darkness, but only framed by it). If we are avid film watchers, we probably get closer to Keedus's real talent during the consecutive readings and notice how he presents the real and plausible as supernatural using the subtle devices of lighting and camera angles.

In the most expressive memory/dream sequence, the boy runs and catches up with a train as the intermittent darkness looms and the sounds of a sex act are heard. The boy searches for somebody - we soon realise, for his mother. He sees several copulating couples, strange and lascivious people in the train's corridor and compartments, emerging from the dark for a moment. The allusion of an orgy and social disruption can be grasped at the connotative level. Once again, as the view is partially obstructed, the viewer is not entirely transported into subjectivity where his/her own allusion could take over, but rather to a dream-like state where the borders of the entities are unclear and the identity of persons or spaces have not been established as firmly as in a familiar, well-lit environment.

We see little darkness-induced subjectivity in Georgica, but we should consider other similar mechanisms that would justify the label of art film. According to Grodal's typology, the fourth (actions and processes that deviate in certain ways from normal objective actions and processes) and sixth (deviant emotional phenomena and reactions) causes of subjectivity are eminently relevant. The first and second factors also have a modest influence. Actions are continuously performed, though not so fast as in classical narrative films. The represented space offers some obstacles: the film uses few establishing shots, thereby not disrupting the simulation, but slowing it down. Each new mise-en-scène is usually 
presented with a close-up. The eccentric characters, uttering cryptic words (the inner voice of both characters is represented), performing incomprehensible actions or performing comprehensible actions too long, fall into the fourth and sixth categories and are probably the most significant subjectivity-inducing devices in Georgica.

Letters to Angel, Keedus's fourth feature film, carries similar dystopic moods. Jeremia Juunas Kirotaja (Tõnu Oja), a middle-aged man, comes to his father's funeral from Afghanistan where he has been an Islamic fighter. He also wants to find out about his daughter called Angel, whom he has never seen. The existence of Angel is not verified, only traces of her can be found in people's memories. The most vivid presence she ever achieves is in Kirotaja's letters. Kirotaja arrives is a neglected small town with weird inhabitants. The ironic glance of the filmmaker presents it as a metaphor for a small state on the periphery of Europe or civilisation, where capitalist ideology has almost suffocated humanity. I will also highlight two sequences of darkness from Letters to Angel.

In the opening shots, Kirotaja wanders through the night in an Afghan settlement, dark streets bordered with small shops and tea houses, emitting light with the hum of noise and cars lazily driving by. At a distance, the peacefully interacting people are faintly seen, but no connection is made between them and the protagonist. The shaky, handheld camera follows him, and soon the voiceover begins to recite his thoughts. Darkness blurs most of his features. The choice of lighting (the seemingly amateurish avoidance of artificial light allows most of the scene to disappear from our view) has a clear and elaborate purpose. It takes the viewer - after she/he has been familiarised with the depicted environment and sees no new affordance - into the "unfocused default mode". However, this mode is not created for the purpose of subjectivity. The purpose is to set an actionneutral background for the voiceover, which carries important ideas for the subsequent narrative.
The other segment is relatively short ( $20 \mathrm{sec})$ and the description of its neighbouring shots is needed in order to provide meaning to it. Kirotaja gives a ride to a young cellist, a girl named Merily (Mirtel Pohla) who is living with a rich and eccentric man named Elvis (Rain Simmul) who has a threatening manner; he is under the influence of drugs and has repeatedly promised to kill his girlfriend. He is paranoid and has even previously paid Kirotaja to assassinate Merily - obviously on a whim. The huge house they inhabit is shadowy, filled with video projections on the walls. We hear low, threatening sounds in the audio track. The girl starts to play the cello for Kirotaja, but the private concert is interrupted by a sudden phone call. Kirotaja is summoned by the owner of the car, Senta (Ragne Pekarev), another unstable resident of the depressing town. Kirotaja returns his down payment to the half-conscious, drug-dozed Elvis and leaves the house, hearing Merily's distant screams. After the protagonist has left, the camera lingers in the same position for 20 seconds. Here, the mise-en-scène is complicated and multi-layered. The shot is aimed through a door with several square glass panels. There is a gloomy room behind the door where we see the contours of Merily, walking around in distraction and desperation, the cello discarded on the floor. An additional layer of the frame consists of the black-and-white video projections on the walls, adding their eerie connotations. Many viewers would probably agree that the word "satanic" is appropriate for characterising the mood that is further influenced by the sound track, the same droning bass strings and the screams of the girl, heard repeatedly.

The cognitive processes of registering the contents of the frame and the action of the girl take less than half of these 20 seconds. The remaining time will likely transfer the viewer's mind into a brief state of subjectivity, giving some time to reflect on Merily's possible fate or to draw some generalising parallels between the life of this dysfunctional couple, the passive and rather hopelessly drifting protagonist and even the 
"real world" in general that looms behind every fictional world.

In Letters to Angel we once again encounter the rather complicated use of darkness. The darkness does not function alone, but co-acts with other devices, shutting off the simulation only once for a very limited time (second example). The second example was given in order to demonstrate the mechanism for inducing connotative meaning and to show how the freshly induced subjective sequence relies heavily on the preceding shots, letting the previously presented ideas echo in its timespace.

Letters to Angel is once again a remarkably story-driven film. As in Keedus's other feature films, the story encompasses several layers of time, explicated through the characters' lines, memories, or altered locations (the Afghanistan episodes were filmed in Mauritania). The time structure, the restrained narrative pace, outstanding dialogues (written, as in Keedus's other films, in cooperation with the writer Madis Kõiv), and once again, the estranging miseen-scène with eccentric characters are the most explicit signs of an art film.

\section{ÖUNPUU'S INTRICATE COMPOSITIONS}

Autumn Ball, Õunpuu's first full-length film, is an adaptation of a novel by the celebrated Estonian postmodern author Mati Unt. The film won the Horizons Award at the Venice Film Festival. This is the highest international recognition any Estonian film has ever received. Õunpuu is known as a talented maverick who never graduated film school and has a background as a painter and writer.

Autumn Ball features the same core ensemble of actors as Õunpuu's debut short called Empty (Tühirand, Estonia, 2006), finely illustrating his method as a director who partly belongs to the cast himself, having abundant experience with and an intimate knowledge of his cast, and therefore enjoying better access to his actors' hidden capabilities. In Autumn Ball, urban alienation and relationship problems prevail. The protagonist, a writer in existential crisis, is played by Rain Tolk. The character is again named Mati, like the protagonist in Empty. An interesting detail is that in the novel the character's name is Eero, not Mati. This can be interpreted as a special homage to Mati Unt, the author of the literary texts, or even, a disguised attempt to make a film about Mati Unt himself. Below, I will look at three sequences from Autumn Ball in which darkness functions, one way or another, in connection with subjective feelings.

In the 40-second night scene shot on the highway (16 minutes into the film) we see one of the protagonists, architect Maurer (Juhan Ulfsak) driving home. The driving scene is too long for a classical narrative film and presented in a distinct audiovisual language (although the partial subjectivity of the driving scenes even in such mainstream texts as Easy Rider (USA, 1969, Dennis Hopper) are a matter for further debate). There are two main features that differ from classical, simulation-wise representation. First, the actor's face is mostly obscured by distance and darkness, so it is barely discernible and the viewer may have trouble recognising Maurer. Secondly, there is no diegetic sound, only the slow jazz-influenced soundtrack. Still, we can consider this sequence partially functional in the sense of storytelling, showing a character driving home at night. At the same time, the subjective mood is nearby and lurking.

The second sequence of darkness begins around 50 minutes into the film in a nightclub, party or concert (which one is not apparent). We see a close-up of drunken Mati, with no extra light directed at his face and the camera pulling in and out of focus. In contrast to the various other examples, here darkness, along with the focus changes, works in service of the character simulation, conveying the state of a drunken person. Next, we see people dancing, drunken Mati wading through the dancers, trying to dance and flirt with some girls. In the middle of the sequence the diegetic sound fades away and an extradiegetic one takes over. The electro-rock tune of the dance floor turns into an experimental, 
dreamy, and sustained sound. The lighting changes slightly and the speed of the shot slows down, approaching slow motion. Now we only see the profile of Mati's head against a blurred, light-coloured background. These changes have subjectivityinducing potential, but they do not go all the way yet. Soon Mati sits down at a table, exhausted, has a cigarette with his head nodding drunkenly. Then the shot starts to dissolve into a night scene of a road, as seen from a moving car's front window. This transition completes with a driving scene similar to the previous one, in terms of colour and mise-en-scène, but now the viewpoint stays inside the car on the driver's position. We do not see who is driving, and soon the shot dissolves back to walking Mati, seen from behind, staggering down the highway with a drunken gait. For a short time, both shots are superimposed onto each other. Finally the sequence fades to black and the music subsides.

At the moment of the first dissolve, subjectivity finally takes over. Here, in confluence with the depressive soundtrack, inferring emptiness and desolation, subjectivity works in favour of connotative meaning. The viewer can be partially interested in where Mati is going or who is driving at the wheel, but the subjective mode now prevails and more likely guides the viewer towards emotions, not character simulation.

The third darkness sequence under observation begins about an hour and ten minutes into the film. We again encounter one of Õunpuu's trademark sequences, combining the night, a highway, and a moving vehicle; the passenger is unseen (or rather non-existent in terms of the storyworld), but the camera mimics the position of his/her gaze. It is shot from the back of a trolleybus, with no lights inside, riding through the streets of nocturnal Tallinn. The shot is accompanied by a very slow and soothing jazz tune. The majority of the frame is filled with the interior of the trolleybus, most of it obscured by darkness. The length of the shot allows the simulation to subside and subjectivity to take over. Then, after thirty seconds, the bus's interior lights go on, followed by a sudden and uplifting, but very elusive note in the jazz tune. The ride continues about ten seconds before the bus stops and one the film's protagonists, Laura (Maarja Jakobson), enters the vehicle with her daughter (Iris Persson). This concludes the subjective sequence and the simulation may take over again.

In order to understand the function of the shot, we must see how it works in syntagmatic relationship with the preceding sequence. The previous sequence ended with a tragicomic surprise or unpleasant punch line. Laura, an unhappy single mother, was romantically approached by a middle-aged man (Raivo E. Tamm) who drove her home in his car, confessing his feelings and proposing marriage to her. After Laura's polite refusal, we saw the man going back to his cosy home where his wife and daughter await. The subsequent subjective trolleybus sequence lets the emotion settle in, giving the viewer time to mull over the unequal positions and social gaming strategies of people, or maybe just think about loneliness, experiencing the emotions that accompany it.

In Autumn Ball, most of the subjective sequences are connected to Mati, distinguishing him and creating a more intimate bond between him and the viewer, making him emotionally significant. The other remarkable feature of subjectivity in Autumn Ball is the use of a rhythm controlling device. Õunpuu uses subjective sequences, more or less consciously, as part of the rhythmic composition. He gives viewers pauses where the accents can reverb and have a deeper effect.

In The Temptations of St. Tony, Õunpuu creates a storyworld that is saturated with symbols, manifesting its deflection from the more or less universally understood concept of "reality". In a classical narrative, the story tends to overshadow the author's ideas and visions preoccupying most of the viewer's receiving capability. Obviously many art house film directors attempt to overcome this by dismantling the story: breaking the cause-effect linkages, creating implausible situations and presenting 
characters without clear and definite goals. In short, doing just the opposite of what Bordwell posits as the inherent features of the classical narrative mode. The Temptations of St. Tony is the only film discussed here that significantly stands up to causeeffect linkages, presenting characters more likely to drift through the situations than act determinedly in order to achieve stereotypical goals as mainstream cinema characters would. What makes The Temptations of St. Tony complicated is a structure in which the simulation sequences are embedded in a wider system. However, the nature of that "master system" or "master style" is not very obvious. It deviates both from simulation and reality, which, according to Grodal, can be stand-alone in respect to each other.

The protagonist Tony (“Tõnu” in Estonian, Taavi Eelmaa) is a well-to-do mid-level manager who suddenly starts to question social reality, attempting to make sense of the world in terms of good and evil. I would favour a more openly ideological interpretation and suggest that Tony starts to see the fundamental drawbacks of capitalism. At the beginning of the film, the simulation seems to work, with certain limitations. Firstly, the black-and-white image provides a significant cue to read it as an art film. Secondly, two of Grodal's causes of subjectivity, "actions and processes that deviate in certain ways from normal objective actions and processes", and "deviant emotional phenomena and reactions" start to take effect. The characters around Tony behave grotesquely; especially three Kafkaesque cops in a dilapidated police station, functioning as a parody of state institutions and proceedings. In the course of the film, we are presented with more and more such details, building up a coherent storyworld on its own terms - one that is probably estranging in most other contexts. As the narrative advances, we are occasionally presented with unmotivated jumps from one mise-en-scène to another, including sequences with more than doubtful causal relations with the prior shots. Here the cause-effect linkages start to unravel. There are no marked borders between the simulation-wise sequences and subjective sequences, i.e., the reality of the storyworld and the visions or hallucinations of the character. Towards the end, the subjectiveness of the film gradually increases. Donald Tomberg has understood the film as a story about Tony losing his mind (Tomberg 2009). As a device, the increasing amount of subjectivity functions well in conveying this. However, the full effect, even if it is intended by Õunpuu, which I doubt, is denied by a probable semantic mistake by the author (only if he had the aforementioned intent of the full effect). As from the beginning, the viewer is presented a rather deviated storyworld, where a sharp and total opposition of "normality-abnormality" or "reality-madness" cannot exist. As I suggested, showing Tony losing his mind is rather a secondary and not a main goal for Õunpuu.

The intricate composition of The Temptations of St. Tony needs more thorough analysis in order to sufficiently describe the functioning of the sign system created by Õunpuu. However, since this is beyond the scope of this article, I turn back to my main goal and discuss two sequences where darkness, one way or another, is involved in the process of creating subjectivity.

The first full disruption of the simulation happens around 27 minutes into the film. Tony is hosting a party at his house. The initially wild bash has calmed down, several people have left. Tony is standing in front of the bathroom mirror, trying to clean his shirt. He looks out the window and suddenly sees his wife (Tiina Tauraite) kissing a guest (Hendrik Toompere, Jr.). With an unchanged expression, Tony looks back at the mirror, and the image fades to black. The screen is black for ten seconds, accompanied by a dark droning ambient sound, quite similar to the soundtrack of some of David Lynch's trademark sequences. Then, a white human shape gradually emerges from the dark, slowly walking towards us. She is a Japanese woman in a white dress; the background is still dark and the face of the woman is blurred. The lighting gives the woman's face a corpse-like appearance. After 50 seconds, the image of the woman 
starts to dissolve into an image of slowly rolling sea waves, shot from a relatively high angle that keeps the coastline and the sky hidden, likely making the waves as abstract as possible in order to prevent the simulation to resume, yet. After twenty seconds of the waves, the dream or hallucination sequence subsides. No extradiegetic sound follows, but an unfocused image of Tony's wife appears. She is lying on a bed, panting, shaking, and moaning seemingly suffering from a terrible nightmare.

At the connotative level that eerie Japanese figure may suggest a feeling of foreboding or death (with the woman having certain undead qualities). The sea waves, on the one hand, have rather universal symbolic value that can encompass a multitude of ideas, converging into a Jungian concept of the subconscious or in general, a chaotic, cosmic uncertainty. On the other hand, as water and waves are rather popular symbols in art films, they have the ability to call upon intertextual links from film history, most notably from Tarkovsky. Technically, that sequence of subjectivity represents the first shift in Tony's mind. As I mentioned earlier, the shift in viewer's mind has already begun before, from the first minutes of the film where reading it as an art film is suggested by the black-and-white medium and by deviant situations and characters.

The next time that the simulation seems to break, or at least take a significant shift, is at 42:20. Here the narrative seemingly arbitrarily cuts to a medium shot of a man wearing a firefighter's helmet and a strange costume; nothing is seen in the background. The mise-en-scène is changed from the previous scene (Tony visiting a beautiful girl Nadezhda (Ravshana Kurkova) in her modest home) without an establishing shot, which is required according to the grammar of classical narrative cinema. The man with a helmet stands silently for ten seconds and then starts a monologue about his life, and about lost hope. There is not indication yet if he is a superimposed character belonging to a meta-level of the narrative, which the narrator sometimes brings into the text in theatre or cinema, or if he belongs to the same diegetic level as Tony. Of the ten seconds of silence, two or three at most is needed to check the image for possible affordances. The remaining time until the monologue begins is open for viewer's subjective thoughts. The monologue partly diffuses the subjectivity, because the story told by the man starts to function in parallel to Tony's story. The viewer remembers the abandonment of Tony's storyworld and starts to hook up with the man's monologue at the same time.

After the minute-long monologue, the film cuts to the same mise-en-scène but to another character - a woman listening to the man's monologue. While the monologue continues, the camera starts to move downwards and gives us a better view of the woman's costume. Only a moment later, a cut is made to the theatre audience, among whom Tony and his wife are sitting. Now the illusion of the two separate diegetic levels is disproved and the simulation mode is totally recovered. Looking back, the viewer realises that his subjectivity had no substantial "basis" and he was only tricked into subjectivity while there was "nothing wrong" with the story. Here, two readings are possible. The first one begins at the indicated time before the monologue; the second one replaces the first at the moment when Tony was represented again.

With the last example, I again used the concept of darkness only metaphorically, but this example was needed for illustrating a sort of playful, double-coded device. A witty, though not inherently original, burst of pseudo-subjectivity was induced. While the subjectivity in the first example of The Temptations of St. Tony was tightly intertwined with the content level of the story, the subjectivity of the second example functioned more on the level of style and poetics, though still providing some commentary on Tony's life and the world he is settled in.

\section{CONCLUSION}

One must be careful when considering sequences of darkness as independent subjectivity-inducing devices. In the case of 
the films by Keedus and Õunpuu, darkness is never a single and stand-alone factor in that sense, but functions in a wider meaning-making system that contains visual and auditory signs from the same sequence. Additionally, the influences of the syntagmatic axis, i.e. the information from the adjacent shots or segments, are often crucial in determining the meaning (and also the subjectivity) of the darkness sequence. This dependence could be looser (the Japanese ghost woman in The Temptations of St. Tony) or stricter (the last example of The Temptations of St. Tony or the cellist girl episode from Letters to Angel). However, the influence from the syntagmatic axis is not always needed.

In contemporary Estonian art film no exceptional or overflowing use of darkness sequences can be detected. Darkness as an Estonian film motif of the century, in the case of the films discussed here, has rather mythical value. Nevertheless, the Estonian cinema of the Soviet era surely deserves further inquiry from the viewpoint of darkness and subjectivity. One of my intuitions is that interesting links between the subjectivity and "normal" style of Soviet cinema can be found in some aspects opposing the Hollywood-based classical narrative cinema as defined by Bordwell, and in others employing its stylistic influences. As for contemporary Estonian art cinema, the body of film is too small to draw pre-emptive conclusions about the art film mode as a whole. In that axis, the first step of development would be setting up a more comprehensive comparison with the characteristic darkness sequences from European or American independent art house films.

It is important to note that the concept of darkness (as a subjectivity-inducing device) can be used in a metaphorical sense, widening the scope of its descriptive power. Therefore, darkness can stand for the obstruction of the spectator's view completely or partially (using various subdevices from an out-of-focus camera to the over-lighting of a scene), blocking the access to the affordances and thus hindering the simulation. The metaphor of dark- ness could even be taken to the level of auditory information, e.g. when diegetic sound gives way to extradiegetic sound that is incomprehensible, estranging, and failing to locate the viewer in the storyworld's time-space.

In most examples, darkness did not stop the simulation totally but rather suspended it. There appears to be a borderline state between simulation and subjectivity, where the inclination towards one or another mode tends to depend on the specific viewer. The slow narrative pace of Keedus's films functions according to this scheme, having the ability to bring some impatient viewers to that in-between state. The description of the mechanics and functions of that borderline state would be one of the most promising subjects for further study in the field of art cinema and subjectivity.

Besides darkness or obstructing the view there are various other subjectivityinducing devices, as seen in Grodal's typology. In Keedus's films, subjectivity works in a sophisticated way. Compared to Õunpuu who may present (in The Temptation of St. Tony) "deviate actions, characters or phenomena", Keedus presents inherently realistic situations and locations, using the stylistic elements that leave an illusion of deviation or, in any case, still have a specific estranging power. In the case of Keedus's films, even Bordwell's main criteria for art film do not apply straightforwardly. The cause-effect relationship is not broken anywhere; on the contrary, his films' deeper meaning is always inherently connected to the cause-effect chain in the long run. Keedus's representation of events, for instance in Georgica, is not exactly linear in a classical sense. Three stories are interlaced therein: the boy's story in the past, the old man's story in the past and their common story in the film's present. If we apply Bordwell's early framework, only the stylistic features distinguish Georgica as an art film; but if we delve deeper, we find subtle and sophisticated poetics everywhere, which retard straightforward simulation. In Keedus's case, the prevailing "art film" 
devices are brilliant at joining the sound with picture, and working with locations, giving the objects the touch of magical realism without any special effects. Õunpuu's films are less story-driven than the films by Keedus. The subjectivity sequences in Õunpuu's films are more explicit, making Õunpuu probably a more self-conscious and more intentional art film director.

It is important to realise that the degrees of reality and subjectivity are not necessarily mutually tied to each other. As Grodal pointed out, the feeling of subjectivity is mostly connected to the lack of affordances and the narrowing of the scope for actions; and there can easily be a storyworld that greatly deviates from our idea for "real", but can still offer a full-time simulation.

The opposition of the simulation mode and the subjective mode constitutes a useful and quite precise instrument for defining art film, which demonstrates cognitive film theory's ability to bring additional systematisation into somewhat scattered film studies. Still, Grodal's emphasis on subjectivity does not diminish the value of Bordwell's initial insights about causality, plausibility, and the ability of advancing the story. In both cases the ultimate question is whether the viewer finds himself in a familiar or unfamiliar situation. As this depends not only on biological but also on cultural constraints, a need still exists for a semiotic approach in order to complement the cognitive aspect.

\section{ACKNOWLEDGEMENTS}

The author thanks the anonymous reviewers, Eva Näripea, and Katre Pärn, for their helpful suggestions and useful comments.

\section{REFERENCES}

Anderson, Joseph 1996. Reality of Illusion. Carbondale: South Illinois University Press.

Andrews, David; Andrews, Christine 2012. 'Film Studies and the Biocultural Turn'. - Philosophy and Literature, $36,1,58-78$

Bordwell, David [1979] 1999. 'The Art Cinema as a Mode of Film Practice.' - Leo Braudy, Marshall Cohen (eds.), Film Theory and Criticism: Introductory Readings. 5th edition. New York: Oxford University Press, 716-724.

Bordwell, David 1986. Narration in Fiction Film. Madison: University of Wisconsin Press.

Bordwell, David 2002. 'Intensified Continuity: Visual Style in Contemporary American Film'. - Film Quarterly, 55, 3, 16-28.

Bordwell, David 2008. Poetics of Cinema. New York: Routledge.

Bordwell, David 2012. 'The Viewer's Share: Models of Mind in Explaining Film'. http://www.davidbordwell.net/ essays/viewersshare.php (12 August 2014).

Buckland, Warren 2000. Cognitive Semiotics of Film.

Cambridge: Cambridge University Press.

Carroll, Noël [1985] 1996. 'The Power of Movies'. -

Noël Carroll, Theorizing the Moving Image. Cambridge: Cambridge University Press, 78-93.

Elsaesser, Thomas; Hagener, Malte 2010. Film Theory: An Introduction Through the Senses. New York, London: Routledge.

Galt, Rosalind; Schoonover, Karl 2010. 'Introduction: The Impurity of Art Cinema'. - Rosalind Galt, Karl Schoonover (eds.), Global Art Cinema: New Theories and Histories. New York: Oxford University Press, 3-27. Gibson, James J. 1986. The Ecological Approach to Visual Perception. New York: Psychology Press.

Grodal, Torben 2009. Embodied Visions: Evolution, Emotion, Culture and Film. New York: Oxford University Press.

Jauss, Hans Robert; Benzinger, Elizabeth 1970

'Literary History as a Challenge to Literary Theory'. New Literary History, 2, 1, 7-37.

Kahneman, Daniel 2011. Thinking, Fast and Slow.

London: Penguin Books.

Kuhn, Annette; Westwell, Guy 2012. A Dictionary of Film Studies. New York: Oxford University Press.

Lakoff, George; Johnson, Mark 1999. Philosophy in the

Flesh: The Embodied Mind and Its Challenge to Western Thought. New York: Basic Books.

Lotman, Juri 2004. Filmisemiootika. Tallinn: Varrak. Odin, Roger 1995. 'For a Semio-Pragmatics of Film'. Warren Buckland (ed.), The Film Spectator: From Sign to Mind. Amsterdam: Amsterdam University Press, 227-235.

Petrie, Graham [1973] 2008. 'Alternatives to Auteurs'. Barry Keith Grant (ed.), Auteurs and Authorship. Malden: Blackwell Publishing, 110-118.

Pierson, Ryan 2010. 'Embodied Visions: Evolution, Emotion, Culture, and Film by Torben Grodal'. - Critical Quarterly, 52, 2, 93-99.

Sellors, Paul 2007. 'Collective Authorship in Film'. The Journal of Aesthetics and Art Criticism, 65, 3, 263-271.

Sinnenbrink, Robert 2012. New Philosophies of Film: Thinking Images. London, New York: Continuum. Sperber, Dan; Wilson, Deirdre 1986. Relevance: Communication and Cognition. Oxford: Basil Blackwell. Stam, Robert 2000. Film Theory: An Introduction. Oxford: Blackwell.

Tomberg, Donald 2009. 'Mu silm ja süda - need on sõjajalal'. - Sirp, 15 October.

Torop, Peeter 1999. 'Harimise kunst'. - Teater. Muusika. Kino, 5, 65-74

Waugh, Linda R. 1980. 'The Poetic Function in the Theory of Roman Jakobson'. - Poetics Today (Roman Jakobson: Language and Poetry), 2, 1a, 57-82. 